\title{
Duration of antibody responses following severe acute respiratory syndrome coronavirus 2 infection
}

\author{
Yao Jiang ${ }^{1} \cdot$ Xiuqi Wei ${ }^{1} \cdot$ Hui Wang ${ }^{1} \cdot$ Guiling $\mathrm{Li}^{1}$ (i)
}

Received: 2 February 2021 / Accepted: 6 November 2021 / Published online: 4 January 2022

(c) The Author(s) 2022

\begin{abstract}
Background Little is known on the duration of anti-severe acute respiratory syndrome coronavirus 2 (SARS-CoV-2) immunoglobulin $\mathrm{G}(\mathrm{IgG})$ antibodies in patients following SARS-CoV-2 infection.

Aims We aimed to determine the duration of the immunoglobulin $\mathrm{G}(\mathrm{IgG})$ and $\mathrm{M}(\mathrm{IgM})$ antibody responses following SARSCoV-2 infection and to evaluate the risk factors for a short duration of anti-SARS-CoV-2 IgG.

Methods We measured antibody responses in 94 patients who had recovered from SARS-CoV-2 infection. The chi-square test and multivariable logistic regression analysis were used to identify risk factors for a short duration ( $<6$ months) of anti-SARS-CoV-2 IgG.

Results IgG antibodies were detectable in all patients until 4 months; 19 (21.8\%) convalescent patients reverted to IgG negative 4-6 months after symptom onset. IgM antibodies decreased significantly to 5.7\% at 4-6 months after symptom onset. Patient characteristics were not associated with a short duration of detectable IgG.

Conclusions A substantial fraction of convalescents may exhibit a transient IgG response following SARS-CoV-2 infection. Our findings suggest that patients who have recovered from SARS-CoV-2 infection should also be vaccinated if their antiSARS-CoV-2 IgG antibodies are undetectable.
\end{abstract}

Keywords COVID-19 · Humoral immunity $\cdot$ Immunoglobulin G · Immunoglobulin M · SARS-CoV-2

\section{Introduction}

Coronavirus disease 2019 (COVID-19), which is caused by severe acute respiratory syndrome coronavirus 2 (SARSCoV-2) infection, was first detected in December 2019 and has since become a global pandemic [1]. As of 19 December 2020, 74,299,042 cases of COVID-19 have been confirmed, and 1,669,982 related deaths were reported. These cases have led to significant challenges for health care systems.

Several published studies have described antibody responses to SARS-CoV-2 in COVID-19 patients [2-8]. Zhao et al. demonstrated that the median seroconversion

Yao Jiang and Xiuqi Wei are co-first authors.

Hui Wang and Guiling Li are co-principal investigators.

Guiling Li

lgluh6714@163.com

1 Cancer Center, Union Hospital, Tongji Medical College, Huazhong University of Science and Technology, Wuhan 430022, China time for $\operatorname{IgM}$ and $\operatorname{IgG}$ were day 12 and day 14, respectively [9]. However, data regarding the duration of anti-SARSCoV-2 antibodies are limited. Thus, we performed this study of convalescent COVID-19 patients to evaluate the duration of antibody responses after SARS-CoV-2 infection, and factors associated with the duration.

\section{Methods}

\section{Study participants}

The Cancer Center, Union Hospital, which is affiliated with the Tongji Medical College of Huazhong University of Science and Technology, was designated as a hospital of admission for COVID-19 patients in Wuhan, China, during the SARS-CoV-2 pandemic. This study included patients admitted to the Cancer Center with laboratoryconfirmed SARS-CoV-2 infection. They had either positive reverse transcription polymerase chain reaction tests for SARS-CoV-2 RNA or positive anti-SARS-CoV-2 
antibody tests. All of them were symptomatic with clinical symptoms including fever, cough, fatigue, dyspnea, myalgia, and diarrhea and had chest radiographic findings of pneumonia.

\section{Collection of specimens and information}

This study was approved by the Union Hospital of Huazhong University of Science and Technology ethics committee (20200191), which waived the requirement for informed consent due to the urgency of the COVID-19 pandemic. Demographic and clinical data were retrieved from medical records and through telephone interviews. Serum samples were collected from each patient between 15 February 2020 and 15 March 2020. Follow-up serum samples were collected between 7 June 2020 and 7 July 2020.

\section{Gold immunochromatographic assay}

Serum IgM and IgG antibodies to SARS-CoV-2 were determined using a commercially available colloidal gold immunochromatographic assay kit (Nanjing Vazyme Medical Technology Co, Nanjing, China), which was approved by the Chinese National Medical Products Administration. Mammalian-cell-expressed recombinant antigens containing the $\mathrm{N}$ protein and the spike protein of SARS-CoV-2 were used to detect the anti-SARS-CoV-2 IgG and IgM antibodies. The sensitivities and specificities are $86.6 \%$ and $96.8 \%$ for IgM, $87.1 \%$ and $99.2 \%$ for IgG, respectively. The tests were performed according to the manufacturer's instructions. Briefly, to detect IgG and IgM, $20 \mu \mathrm{L}$ of serum and $60 \mu \mathrm{L}$ of diluent were added to antigen-coated wells (test card). The test card was incubated at room temperature and the results were read after exactly 10 minutes. Every test card had a control line, and the results were only considered valid when the control line showed.

\section{Statistical analyses}

For the descriptive analysis, continuous variables are presented as medians and interquartile ranges (IQRs), and categorical variables are presented as percentages. The chisquare test was used to test for the significance of differences between groups. A multivariable logistic regression analysis was performed to identify factors associated with a short duration (4-6 months) of anti-SARS-CoV-2 IgG antibody persistence. All statistical analyses were performed using SPSS Statistics, Version 26.0 (IBM Corp., Armonk, NY, USA). Two-sided $P$-values $<0.05$ were considered statistically significant.
Table 1 Results of the first anti-SARS-CoV-2 antibody tests among 94 participants following SARS-CoV-2 infection

\begin{tabular}{|c|c|c|c|c|}
\hline \multirow[b]{2}{*}{$\begin{array}{l}\text { Time after } \\
\text { symptom onset } \\
\text { (days) }\end{array}$} & \multicolumn{2}{|l|}{ IgG } & \multicolumn{2}{|l|}{ IgM } \\
\hline & $\begin{array}{l}\text { No. } \\
\text { samples } \\
\text { tested }\end{array}$ & $\begin{array}{l}\text { No. positive } \\
\text { samples (\%) }\end{array}$ & $\begin{array}{l}\text { No. } \\
\text { samples } \\
\text { tested }\end{array}$ & $\begin{array}{l}\text { No. positive } \\
\text { samples (\%) }\end{array}$ \\
\hline 13-21 & 5 & $5(100.0)$ & 5 & $4(80.0)$ \\
\hline 22-30 & 22 & $22(100.0)$ & 22 & $15(68.2)$ \\
\hline $31-60$ & 67 & $67(100.0)$ & 67 & $47(70.1)$ \\
\hline
\end{tabular}

$I g G$ immunoglobulin $\mathrm{G}, I g M$ immunoglobulin $\mathrm{M}$, SARS-CoV-2 severe acute respiratory syndrome coronavirus 2

\section{Results}

A total of 94 patients were included in the cohort, of whom 71 patients were diagnosed by polymerase chain reaction assays of nasal and/or pharyngeal specimens, and 23 were diagnosed on the basis of serum anti-SARS-CoV-2 antibody detection, symptoms compatible with COVID-19, and typical chest radiographic findings. Their median age was 65 years (IQR 58-69 years), and 48 (51.1\%) were women. Fifty-two patients (55.3\%) had comorbidities, including hypertension, diabetes, and coronary heart disease. Of the 94 patients, $49(52.1 \%)$ had severe disease and $25(26.6 \%)$ had been treated with systemic steroids.

All 94 patients underwent two IgG and IgM antibody tests. The first tests were conducted a median of 35 days (IQR: 29-39 days) after the onset of symptoms, and the first anti-SARS-CoV-2 IgG antibodies were all positive (Table 1). The second tests were conducted a median of 147.5 days (IQR 132-160 days) after the onset of symptoms. As shown in Table 2, 19 patients $(21.8 \%)$ were $\operatorname{IgG}$ negative by $4-6$ months after symptom onset.

The trend in anti-SARS-CoV-2 IgM positivity differed from that of IgG. At 13-21 days after symptom onset, the IgM positivity rate was $80 \%$. This rate decreased significantly to $5.7 \%$ at $4-6$ months after symptom onset.

Of the 87 patients who had their second anti-SARSCoV-2 IgG and IgM antibody tests 4-6 months after

Table 2 Results of second anti-SARS-CoV-2 antibody tests among 94 participants following SARS-CoV-2 infection

\begin{tabular}{|c|c|c|c|c|}
\hline \multirow[b]{2}{*}{$\begin{array}{l}\text { Time after } \\
\text { symptom onset } \\
\text { (days) }\end{array}$} & \multicolumn{2}{|l|}{ IgG } & \multicolumn{2}{|l|}{ IgM } \\
\hline & $\begin{array}{l}\text { No. } \\
\text { samples } \\
\text { tested }\end{array}$ & $\begin{array}{l}\text { No. positive } \\
\text { samples (\%) }\end{array}$ & $\begin{array}{l}\text { No. } \\
\text { samples } \\
\text { tested }\end{array}$ & $\begin{array}{l}\text { No. positive } \\
\text { samples (\%) }\end{array}$ \\
\hline 91-120 & 7 & $7(100.0)$ & 7 & $1(14.3)$ \\
\hline $121-180$ & 87 & $68(78.2)$ & 87 & $5(5.7)$ \\
\hline
\end{tabular}

$I g G$ immunoglobulin $\mathrm{G}, I g M$ immunoglobulin $\mathrm{M}$, SARS-CoV-2 severe acute respiratory syndrome coronavirus 2 
symptom onset, we performed a comparative analysis of clinical and demographic characteristics and observed no significant differences in age, sex, illness severity, comorbidities, or systemic steroid treatment between patients who remained $\mathrm{IgG}$-seropositive and those who became seronegative over time. Multivariable logistic regression analysis, including age, sex, the severity of illness, comorbidities, and systemic steroid treatment, did not identify any factors significantly associated with a short duration of detectable IgG.

\section{Discussion}

A previous study showed that the seroconversion of most COVID-19 patients occurs between 7 and 14 days after symptom onset [10]. However, the duration of antiSARS-CoV-2 antibodies and risk factors associated with the duration are still uncertain. In our study, the first antiSARS-CoV-2 IgG antibodies of 94 patients were all positive. However, about one fifth reverted to an IgG-negative status at 4-6 months after symptom onset. Furthermore, we did not identify any patient characteristics that were significantly associated with the persistence of IgG. Yang et al. [11] reported a rapid decline of anti-SARS-CoV-2 antibody levels in 34 patients with mild COVID-19 during an observation period of approximately 90 days. However, they also added that it is difficult to extrapolate beyond this time period because it is likely that the decay will decelerate. Gudbjartsson et al. analyzed serum samples from 1215 persons who recovered from SARS-CoV-2 infection and found that $91.9 \%$ remained seropositive within 4 months of SARS-CoV-2 infection [12]. In our study, the positivity rate of anti-SARS-CoV-2 IgG antibody was $100 \%$ at 4 months after symptom onset and then declined rapidly. This suggests that immunity to SARS-CoV-2 disappears 4-6 months after infection in some individuals, who may then become reinfected. To our knowledge, our study is the longest longitudinal anti-SARS-CoV-2 IgG and IgM followup reported to date.

A previous study found that higher antibody titers were independently associated with more severe disease [9]. Long et al. [13] showed that $40.0 \%$ of asymptomatic individuals and $12.9 \%$ of symptomatic individuals became $\mathrm{IgG}$ seronegative during the early convalescent phase ( 8 weeks after hospital discharge), and they suggested that asymptomatic individuals may develop a weaker immune response to SARS-CoV-2 infection. In our cohort, we found that neither severity of illness nor age, sex, comorbidities, and systemic steroid treatment were associated with a short duration of detectable IgG.

\section{Conclusions}

Our data suggest that a substantial fraction of convalescents may exhibit a transient $\mathrm{IgG}$ response following SARS-CoV-2 infection and revert to a seronegative status within 4-6 months after symptom onset; the duration of this response is not associated with symptom severity. Furthermore, our findings raise concerns about the possibility of reinfection among previously exposed individuals. Thus, patients who have recovered from SARS-CoV-2 infection should also be vaccinated if their anti-SARSCoV-2 IgG antibodies are undetectable.

Acknowledgements We would like to thank the patients who participated in the present study. We thank Editage [http://www.editage. com] for editing and reviewing the English language quality in this manuscript.

Authors' contributions All authors contributed to the study conception and design. Material preparation was performed by Xiuqi Wei. Data collection and analysis were performed by Yao Jiang. The first draft of the manuscript was written by Yao Jiang and all authors commented on previous versions of the manuscript. All authors read and approved the final manuscript.

Funding This research did not receive any specific grant from funding agencies in the public, commercial, or not-for-profit sectors.

Availability of data and materials The data used to support the findings of this study are available from the corresponding author upon request.

Code availability Not applicable.

\section{Declarations}

Ethics approval This study was approved by the Union Hospital of Huazhong University of Science and Technology ethics committee (20200191).

Consent to participate Requirement for written informed consent was waived by the institutional ethics board due to the urgency of the COVID-19 pandemic.

Consent for publication Not applicable.

Conflict of interest The authors declare that they have no conflict of interest.

Open Access This article is licensed under a Creative Commons Attribution 4.0 International License, which permits use, sharing, adaptation, distribution and reproduction in any medium or format, as long as you give appropriate credit to the original author(s) and the source, provide a link to the Creative Commons licence, and indicate if changes were made. The images or other third party material in this article are included in the article's Creative Commons licence, unless indicated otherwise in a credit line to the material. If material is not included in the article's Creative Commons licence and your intended use is not permitted by statutory regulation or exceeds the permitted use, you will need to obtain permission directly from the copyright holder. To view a copy of this licence, visit http://creativecommons.org/licenses/by/4.0/. 


\section{References}

1. Huang C, Wang Y, Li X et al (2020) Clinical features of patients infected with 2019 novel coronavirus in Wuhan, China. Lancet 395:497-506

2. Iwasaki A, Yang Y (2020) The potential danger of suboptimal antibody responses in COVID-19. Nat Rev Immunol 20:339-341

3. Lee YL, Liao CH, Liu PY et al (2020) Dynamics of anti-SARSCov-2 IgM and IgG antibodies among COVID-19 patients. J Infect 81:e55-e8

4. Long QX, Liu BZ, Deng HJ et al (2020) Antibody responses to SARS-CoV-2 in patients with COVID-19. Nat Med 26:845-848

5. Lou B, Li TD, Zheng SF et al (2020) Serology characteristics of SARS-CoV-2 infection since exposure and post symptom onset. Eur Respir J 56:2000763

6. Ni L, Ye F, Cheng ML et al (2020) Detection of SARS-CoV2 -specific humoral and cellular immunity in COVID-19 convalescent individuals. Immunity 52:971-977.e3

7. Petherick A (2020) Developing antibody tests for SARS-CoV-2. Lancet 395:1101-1102

8. Xiang F, Wang X, He X et al (2020) Antibody detection and dynamic characteristics in patients with COVID-19. Clin Infect Dis 71:1930-1934
9. Zhao J, Yuan Q, Wang H et al (2020) Antibody responses to SARS-CoV-2 in patients of novel coronavirus disease 2019. Clin Infect Dis 71:2027-2034

10. Vabret N, Britton GJ, Gruber C et al (2020) Immunology of COVID-19: current state of the science. Immunity 52:910-941

11. Ibarrondo FJ, Fulcher JA, Goodman-Meza D et al (2020) Rapid decay of anti-SARS-CoV-2 ANTIBODIES IN PERSONS WITH MILD Covid-19. N Eng J Med 383:1085-1087

12. Gudbjartsson DF, Norddahl GL, Melsted P et al (2020) Humoral immune response to SARS-CoV-2 in Iceland. N Eng J Med 383:1724-1734

13. Long QX, Tang XJ, Shi QL et al (2020) Clinical and immunological assessment of asymptomatic SARS-CoV-2 infections. Nat Med 26:1200-1204

Publisher's Note Springer Nature remains neutral with regard to jurisdictional claims in published maps and institutional affiliations. 